\title{
A NUMERICAL STUDY ON THE EFFECT OF CONCRETE INFILL AND INTUMESCENT COATING TO FIRE-RESISTANT BEHAVIOUR OF STUB ELLIPTICAL STEEL HOLLOW SECTIONS UNDER AXIAL COMPRESSION
}

\author{
X.H. Dai ${ }^{1}$ and D. Lam ${ }^{2, *}$ \\ ${ }^{1}$ Lecturer, School of Engineering Design and Technology, \\ University of Bradford, Bradford, BD7 1DP, UK \\ ${ }^{2}$ Professor, School of Engineering Design and Technology, \\ University of Bradford, Bradford, BD7 1DP, UK \\ *(Corresponding author: E-mail: d.lam1@bradford.ac.uk)
}

Received: 24 March 2013; Revised: 3 July 2013; Accepted: 24 September 2013

\begin{abstract}
This paper presents a numerical study on the effect of concrete infill and intumescent coating to the fire resistant behaviour of stub elliptical concrete filled steel tubular (CFST) columns under standard fire. The selected elliptical steel hollow sections in this research cover the common used elliptical sections in current construction market; from $200 \times 100 \mathrm{~mm}$ to $500 \times 250 \mathrm{~mm}$ with wall thicknesses varying from 5 to $12.5 \mathrm{~mm}$. Temperature distribution, critical temperature and fire exposing time of selected stub elliptical columns with concrete infill and other intumescent coating fire protection options under axial compression were extracted from numerical simulations using commercial FE package ABAQUS. Based on the comparison and analysis of the obtained results, the effect of concrete core and external intumescent coating to the thermal and structural fire-resistant behaviour of stub elliptical columns are discussed. Simple formulae are proposed to assess the critical steel temperature and maximum axial compressive load of stub elliptical CFST columns in standard fire.
\end{abstract}

Keywords: Elliptical hollow section, temperature development, critical temperature, fire exposing time, concrete infill, intumescent coating, numerical modelling

\section{INTRODUCTION}

There are many forms of fire protection methods which may apply to structural steel and composite structures to promote their fire resistance ability. Applying intumescent coating is one of the commonly used methods although the intumescent coatings themselves do not provide any enhancement to the structural capacity. Due to the inert property of concrete and its poor thermal conductivity, it could be smartly deployed to provide fire resistance to the steel members and offered additional load resistance. When a CFST column is subjected to fire, the concrete core acts as a heat sink and this resulted in a reduction in steel temperature when comparing with an equivalent unfilled steel hollow section subjected to the same fire exposure. Because of the concrete temperature rises much slower than that of the steel tube, the concrete core could provide appropriate load bearing capacity even when the steel tube reached its capacity. In many situations when higher fire resistance period is required, using steel hollow sections even with concrete infill cannot meet the fire resistant requirement; therefore intumescent coating or other forms of external fire protection to the steel members may be used to enhance the fire resistance.

Previous researches carried out on CFST members exposed to fire by experimental studies and numerical methods have provided some important insights into structural fire behaviour of this kind of steel concrete composite members (Tao et al. [1], Han and Lin [2], Han et al. [3], Huo et al. [4], Zha [5], Hong and Varma [6], Espinos et al. [7 - 8]). However for the unprotected CFST columns in standard fire, Dai and Lam [9] showed that the temperature of steel section rises quickly within a short exposure time and reached the critical design temperature, this suggests that additional 
measurement such as external fire protection or fire shading is required to improve the fire resistance in practice. Applying intumescent coating is an effective method to reduce the steel temperature development (Corus Construction \& Industrial [10]). The intumescent coating provided by different suppliers might be with different properties and performance, such as different dry film thickness and fire protection time etc. Dai et al. [11, 12] investigated the thermal behaviour of steel joint assemblies with a typical intumescent coating (cellulosic solvent based) and the results illustrated that the intumescent coating provided an excellent property in impeding the temperature development of steel members in fire.

In active fire resistance design, the critical temperature and critical exposing duration of a structural member are the most important design parameters. They might be affected by many factors such as building type, occupancy, loading, geometry and material properties etc. For CFST columns with same loading ratio and boundary conditions, the member material properties and geometrical characteristics will dominate these design parameters. The main objective of this research is to investigate the effect of intumescent coating and concrete infill to fire resistance of elliptical stub CFST columns with various elliptical hollow section dimensions and intumescent coating; it focused on comparison and analysis of temperature development, critical temperature and fire exposure time of elliptical stub CFST columns with a fixed load ratio. The critical temperature defined in this paper is defined as the average steel tube temperature in which the steel material reached its yield strength at the prescribed load ratio above which the column will experience a progressive deformation. The prescribed load ratio of elliptical stub columns in fire is assumed to be 0.5 which is closed to the design load ratios (0.47 and 0.66) provided in EN1994-1-2 [13] for CFST columns with circular and rectangular sections. The critical fire exposing time is defined as the fire period when the steel tube reached its critical temperature.

\section{ELLIPTICAL SECTIONS AND FIRE PROTECTION OPTIONS}

For unprotected CFST members with different sectional shapes, such as circular (CHS), elliptical (EHS), square (SHS) and rectangular (RHS) shapes in standard fire, the temperature distribution in steel cross-section is not uniform. The maximum difference in temperature may be up to $70{ }^{\circ} \mathrm{C}$ when exposed to a standard ISO fire (ISO 834 [14]) for 60 minutes, with the exception for CHS where the temperature difference is less than $4{ }^{\circ} \mathrm{C}$. The non-uniformity of temperature distribution of steel section changes with the different section shapes and dimensions. The study carried out by Dai and Lam [9] showed that the compressive behaviour of elliptical stub CFST columns in fire is not as good as composite columns with circular sections but better than columns with square and rectangular sections due to the circular hollow sections provide better confinement effect to concrete core and less stress concentration. This research is to investigate the effect of intumescent coating and concrete infill to the fire resistant behaviour of elliptical steel hollow sections without reinforcement in the concrete core.

To investigate the effect of intumescent coating for fire protection to elliptical stub CFST columns, thermal analysis (heat transfer) and stress-strain analysis (both in ambient and elevated temperature) were performed for 9 selected column specimens with 6 fire protection options. These selected stub specimens covered the section sizes ranges from $200 \times 100 \mathrm{~mm}$ to $500 \times 250 \mathrm{~mm}$ with various wall thicknesses from 5.0 to $12.5 \mathrm{~mm}$. The fire protection options included different intumescent coating dry film thicknesses $(0.0,1.0,1.5$ and $2.0 \mathrm{~mm})$. In addition, unfilled elliptical steel hollow sections in fire are also compared with elliptical CFST columns to investigate the effect of the concrete infill. 


\section{MATERIAL PROPERTIES}

It is well understood that the mechanical and thermal properties of steel and concrete are very different in fire design. Steel is recognized as a highly thermal conductive material to concrete although the strength and stiffness of both steel and concrete will reduce as the temperature increases. In this paper, all steel hollow sections are assumed to be hot finished. As aforementioned, the aim of this research is to investigate the effect of intumescent coating and concrete infill to the structural fire-resistant behaviour of CFST columns; therefore, identical steel material properties were adopted for the selected steel hollow sections to eliminate the influence of the steel material properties. In addition, the concrete infill for all the composite columns was assumed to be identical.

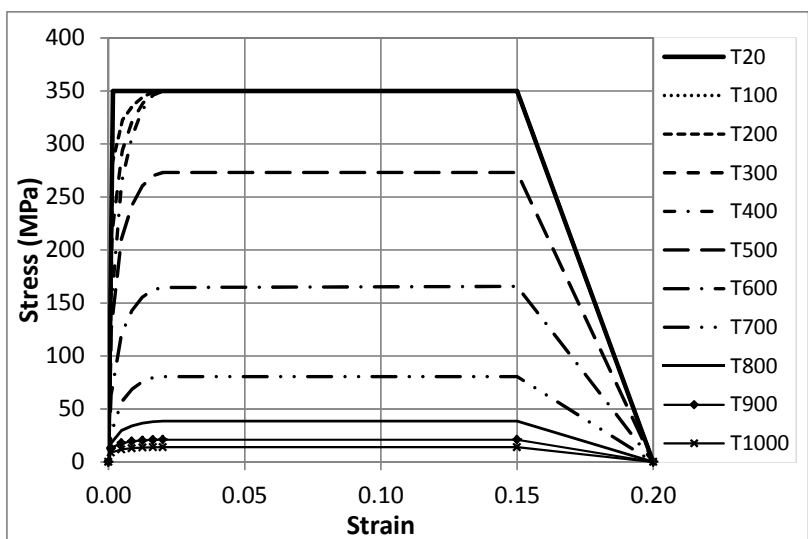

(a). Steel

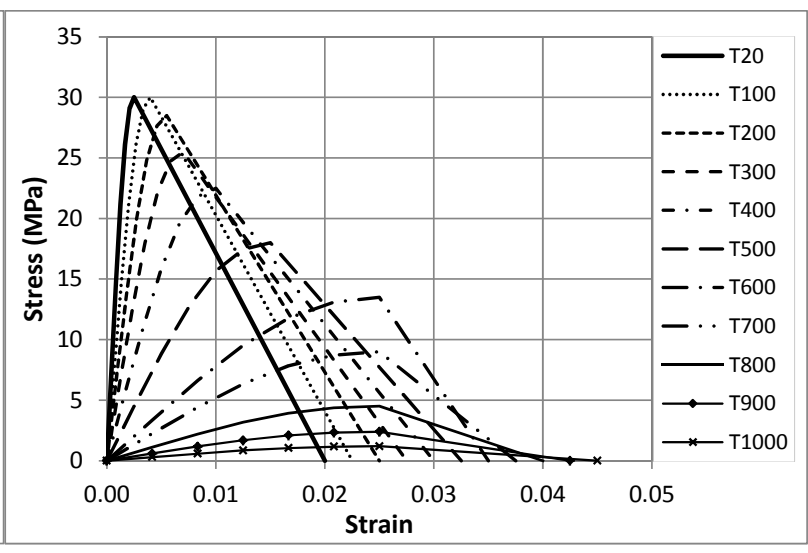

(b). Concrete

Figure 1. Stress-strain Curves of Steel and Concrete at Elevated Temperatures

The stress-strain curve of steel material at room temperature $\left(20^{\circ} \mathrm{C}\right)$ is defined by $\mathrm{T}_{20}$ curve in Figure 1(a). The yield strength, $f_{y}$ and elastic modulus, $E_{s}$ was assumed to be $350 \mathrm{~N} / \mathrm{mm}^{2}$ and $210000 \mathrm{~N} / \mathrm{mm}^{2}$ respectively for all the steel hollow sections. The reduction factors for strength and deformation of steel material at elevated temperatures is in accordance to the EN1993-1-2 [15] for carbon steel and as shown in Figure 1(a). The maximum compressive strength of concrete $f_{c}$ and corresponding strain $\varepsilon_{c}$ was assumed to be $30 \mathrm{~N} / \mathrm{mm}^{2}$ and 0.003 respectively. In Figure 1(b), the $\mathrm{T}_{20}$ curve represents the stress-strain relationship of concrete at room temperature. The reduction factors for concrete strength and deformation at elevated temperatures is in accordance to EN1994-1-2 and Figure 1(b) shows the stress-strain curves at all the different temperatures. The thermal properties of both steel and concrete were in accordance to the thermal properties of carbon steel and normal weight concrete given in the EN1993-1-2 and EN1994-1-2 and as shown in Figure 2 , the moisture content of the concrete was assumed to be zero. The thermal conductivity of the intumescent coating (Figure 2a) is taken to be the average value of those extracted from the experiments carried out by Dai et al. [12]. The specific heat of the intumescent coating was assumed to be $1000 \mathrm{~J} / \mathrm{kg} / \mathrm{K}$. The densities of steel, concrete and intumescent were assumed to be $7850 \mathrm{~kg} / \mathrm{m}^{3}, 2400 \mathrm{~kg} / \mathrm{m}^{3}$ and $1300 \mathrm{~kg} / \mathrm{m}^{3}$ respectively. 

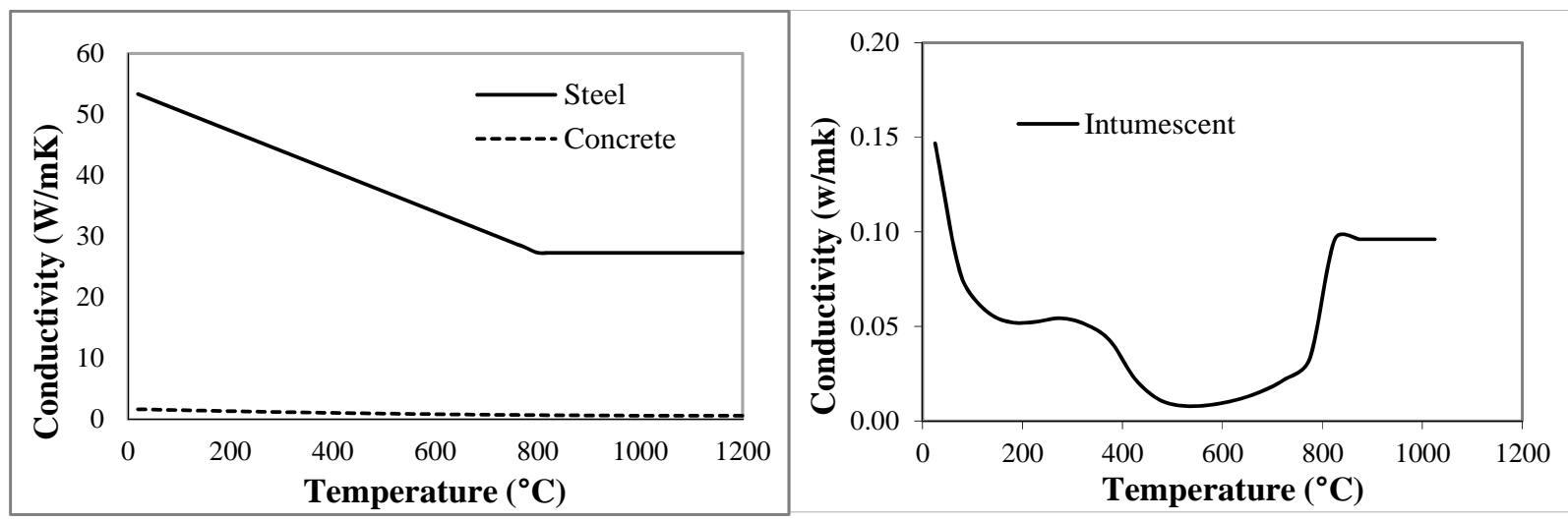

(a) Thermal conductivity

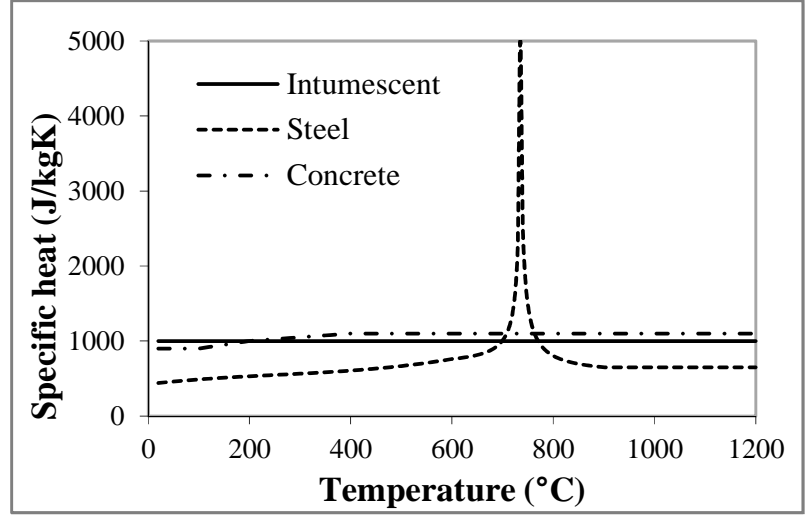

(b) Specific heat

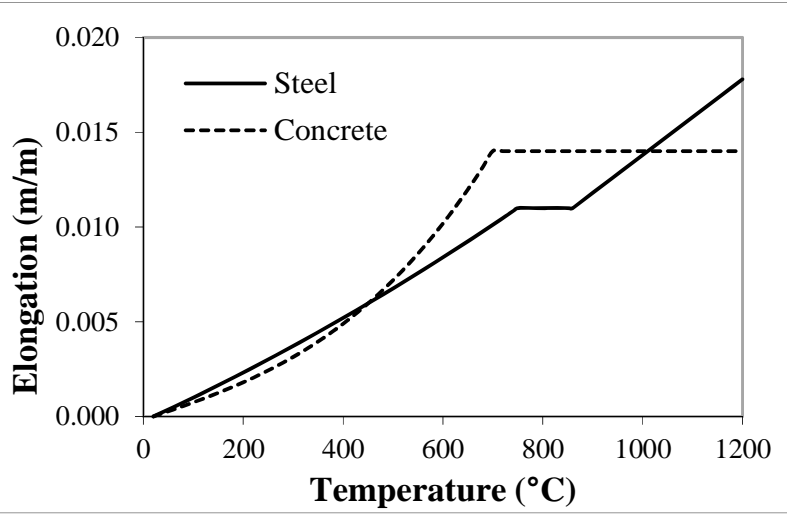

(c) Elongation

Figure 2. Thermal Properties of Steel, Concrete and Intumescent Coating Adopted in this Research

\section{NUMERICAL PROCEDURE}

When a structural member subjected to fire, the heat flux will transfer through the member surface and increases the member temperature. In simple fire design for steel, the steel temperature is assumed to be uniformly distributed, however this assumption is not appropriate for CFST members due to the temperature difference in steel and concrete, therefore advanced heat transfer analysis is usually performed to determine the temperature distribution.

In the research presented in this paper, a non-linear heat transfer modelling developed using commercial software ABAQUS was used to determine the temperature distribution of each selected composite column under standard ISO fire. During the fire exposure, heat is transferred to the steel tube surface through convection and radiation and into the member through heat conductive mechanisms. In the modelling, the convective coefficient was taken to be $25 \mathrm{~W} / \mathrm{m}^{2} \mathrm{k}$ as recommended in EN1991-1-2 [16] and the effective surface emissivity of 0.5 was used. For CFST columns in fire, it is possible that a gap will form between the steel hollow section and concrete core due to their different expansion. Research by Ding and Wang [17] indicated that introducing an air gap will give a higher fire resistance times than without a gap for CFST columns without external fire protection. However, for CFST columns with high degree of external fire protection, introducing an air gap might lead to prediction of lower column fire resistance period but the difference of fire resistance period is very small. In this study, to simplify the heat transfer analysis, the possible air gap between the steel tube and concrete core during fire was not taken into consideration; hence the heat flow may directly conduct from steel tube into the concrete core. 
For column sections with intumescent coating, it was assumed that the intumescent coating thickness is uniform and effectively affixed to the steel surface. In the heat transfer analysis, the 3D heat transfer element was used for the intumescent. Due to the highly inert property of intumescent coating, which is very different from the steel material, therefore the element size and contact surface between the steel section and the coating is sensitive to the accuracy of the heat transfer analysis. A sensitivity study was carried out and the comparison is shown in Figure 3. It indicated that for the intumescent coating with dry film thickness less than $2.0 \mathrm{~mm}$, if the elements were dividing into 6 layers or more with the concrete and steel element size no more than $50 \mathrm{~mm}$, then the influence of element size to the steel and concrete temperature will be less than $10{ }^{\circ} \mathrm{C}$ and $5{ }^{\circ} \mathrm{C}$ respectively. Therefore, 6 layers of elements with element size of $50 \mathrm{~mm}$ were adopted in the thermal analysis. The thermal properties of steel, concrete and intumescent shown in Figure 2 were used throughout.
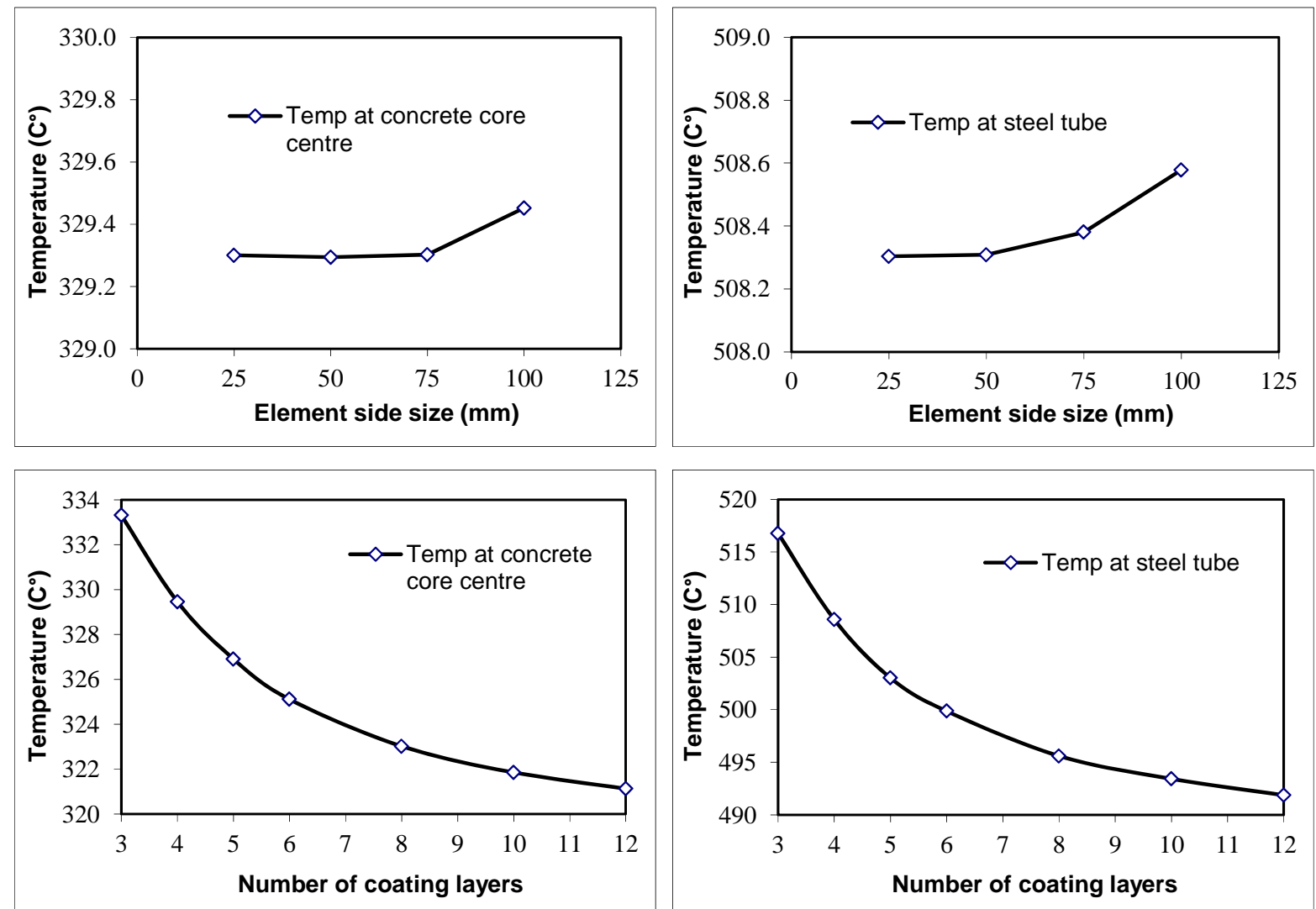

Figure 3. Element Size Sensitivity Comparison

\section{TEMPERATURE DEVELOPMENT}

The following abbreviations are adopted throughout this paper to specify the member individual features related to concrete infill and intumescent coating of the stub CFST columns:

US: $\quad$ unfilled steel hollow section without intumescent coating,

PS: $\quad$ unfilled steel hollow section with intumescent coating (dry film thickness $1.0 \mathrm{~mm}$ ),

UP: $\quad$ CFST column without intumescent coating,

PP: $\quad$ CFST column with intumescent coating (dry film thickness $1.0 \mathrm{~mm}$ ),

PPA: $\quad$ CFST column with intumescent coating (dry film thickness $1.5 \mathrm{~mm}$ ),

PPB: $\quad$ CFST column with intumescent coating (dry film thickness $2.0 \mathrm{~mm}$ ), 
Figure 4(a) presents an example for temperature development in steel tube of selected columns with steel hollow section $200 \times 100 \times 10 \mathrm{~mm}$ and different fire protection options mentioned above. It can be observed that with an unfilled steel hollow section without fire protection (US), the steel temperature rose rapidly reaching $600{ }^{\circ} \mathrm{C}$ in less than 15 minutes. When an equivalent steel hollow section was filled with concrete but without intumescent coating (UP), the steel temperature development was lower than the unfilled column (US) but higher than the unfilled section with intumescent coating protection (PS), however if the same steel hollow section with both infill concrete and intumescent coating (PP, PPA and PPB), the temperature development in steel tubes reduced significantly and is below $600{ }^{\circ} \mathrm{C}$ with the fire exposure time well beyond 60 minutes. Figure 4(b) shows that the temperature at the concrete core centre, it can be observed that the temperature in the centre of core of the composite column without intumescent coating (UP) is much higher than the temperatures in the centre of the CFST columns with intumescent coating (PP, PPA, PPB) owing to the intumescent coating blocking the heat flux to the composite columns.

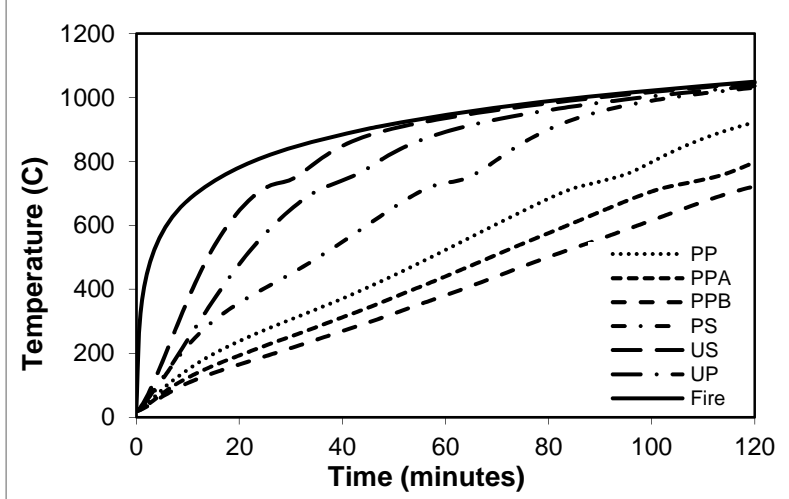

(a) Average temperature at steel tube

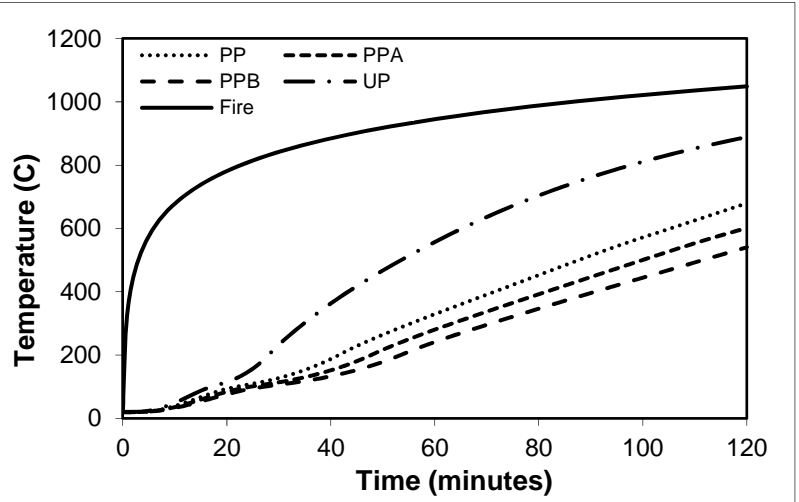

(b) Temperature at core centre

Figure 4. Effect of Intumescent Coating and Concrete Core on Temperature Development of Steel Hollow Section EHS200×100×10mm

For the other CFST columns with different wall thicknesses $(5.0 \mathrm{~mm}, 6.3 \mathrm{~mm}, 8.0 \mathrm{~mm}$ and $12.5 \mathrm{~mm})$ and different section dimensions $(250 \times 125 \times 10 \mathrm{~mm}, 300 \times 150 \times 10 \mathrm{~mm}, 400 \times 200 \times 10 \mathrm{~mm}$ and $500 \times 250 \times 10 \mathrm{~mm}$ ), similar temperature development curves were also extracted from the numerical modelling. In conclusion, the infill concrete helps to lower the temperature of CFST columns in fire; applying intumescent coating also significantly delay the temperature rise in steel hollow section and CFST columns. Table 1 summarizes the steel and concrete core temperatures for all selected columns at 60 and 120 minutes fire exposure.

From Table 1, these following conclusions may be drawn: (1) with the steel wall thickness increases, the steel temperature reduced and the core temperature increased. For the intumescent coating only steel hollow sections, the steel temperature reduced evidently with the increases in the wall thickness; (2) with the column section dimension increased from $200 \times 100 \times 10 \mathrm{~mm}$ to $500 \times 250 \times 10 \mathrm{~mm}$, the steel temperature decreased slightly for the columns with intumescent coating, but the concrete core temperature reduced significantly. 
Table 1. Temperature of Steel Tube and Concrete Core Centre at 60 Minutes and 120 Minutes Fire Exposing for Selected Columns

\begin{tabular}{|c|c|c|c|c|c|c|c|c|}
\hline \multirow{2}{*}{$\begin{array}{l}\text { Fire } \\
\text { time }\end{array}$} & \multirow{2}{*}{$\begin{array}{l}\text { Monitoring } \\
\text { Location }\end{array}$} & \multirow{2}{*}{ Column section } & \multicolumn{6}{|c|}{ Composite column conditions and temperature } \\
\hline & & & US & PS & UP & $\mathrm{PP}$ & PPA & $\mathrm{PPB}$ \\
\hline \multirow{18}{*}{60 minutes } & \multirow{9}{*}{ Steel tube } & EHS200×100×5.0 & 940 & 898 & 895 & 567 & 474 & 410 \\
\hline & & EHS200×100×6.3 & 939 & 841 & 891 & 544 & 464 & 401 \\
\hline & & EHS200×100×8.0 & 937 & 765 & 897 & 539 & 452 & 392 \\
\hline & & EHS200× $100 \times 10.0$ & 935 & 733 & 892 & 524 & 440 & 381 \\
\hline & & EHS200×100×12.5 & 932 & 697 & 884 & 508 & 427 & 370 \\
\hline & & EHS $250 \times 125 \times 10.0$ & 935 & 731 & 876 & 496 & 417 & 357 \\
\hline & & EHS $300 \times 150 \times 10.0$ & 935 & 730 & 866 & 475 & 397 & 340 \\
\hline & & EHS $400 \times 200 \times 10.0$ & 935 & 729 & 853 & 453 & 376 & 322 \\
\hline & & EHS $500 \times 250 \times 10.0$ & 935 & 731 & 846 & 439 & 365 & 313 \\
\hline & \multirow{9}{*}{ Concrete core } & EHS200×100×5.0 & - & - & 519 & 313 & 267 & 229 \\
\hline & & EHS200×100×6.3 & - & - & 529 & 317 & 270 & 232 \\
\hline & & EHS200×100×8.0 & - & - & 542 & 323 & 275 & 237 \\
\hline & & EHS $200 \times 100 \times 10.0$ & - & - & 558 & 329 & 280 & 241 \\
\hline & & EHS $200 \times 100 \times 12.5$ & - & - & 575 & 338 & 287 & 248 \\
\hline & & EHS $250 \times 125 \times 10.0$ & - & - & 389 & 218 & 177 & 152 \\
\hline & & EHS $300 \times 150 \times 10.0$ & - & - & 265 & 138 & 124 & 115 \\
\hline & & EHS $400 \times 200 \times 10.0$ & - & - & 117 & 92 & 84 & 78 \\
\hline & & EHS $500 \times 250 \times 10.0$ & - & - & 79 & 56 & 52 & 48 \\
\hline \multirow{18}{*}{120 minutes } & \multirow{9}{*}{ Steel tube } & EHS200×100×5.0 & 1047 & 1041 & 1036 & 955 & 879 & 771 \\
\hline & & EHS200×100×6.3 & 1047 & 1039 & 1036 & 948 & 859 & 751 \\
\hline & & EHS200×100×8.0 & 1046 & 1036 & 1036 & 938 & 832 & 734 \\
\hline & & EHS $200 \times 100 \times 10.0$ & 1045 & 1031 & 1036 & 922 & 797 & 721 \\
\hline & & EHS $200 \times 100 \times 12.5$ & 1044 & 1020 & 1036 & 900 & 763 & 703 \\
\hline & & EHS $250 \times 125 \times 10.0$ & 1045 & 1030 & 1030 & 882 & 750 & 684 \\
\hline & & EHS $300 \times 150 \times 10.0$ & 1045 & 1030 & 1025 & 842 & 724 & 641 \\
\hline & & EHS $400 \times 200 \times 10.0$ & 1045 & 1029 & 1017 & 792 & 686 & 591 \\
\hline & & EHS500×250×10.0 & 1045 & 1029 & 1013 & 773 & 660 & 565 \\
\hline & \multirow{9}{*}{ Concrete core } & EHS $200 \times 100 \times 5.0$ & - & - & 849 & 675 & 599 & 539 \\
\hline & & EHS $200 \times 100 \times 6.3$ & - & - & 859 & 677 & 599 & 539 \\
\hline & & EHS $200 \times 100 \times 8.0$ & - & - & 873 & 678 & 599 & 540 \\
\hline & & EHS $200 \times 100 \times 10.0$ & - & - & 889 & 679 & 601 & 540 \\
\hline & & EHS200×100×12.5 & - & - & 908 & 682 & 606 & 542 \\
\hline & & EHS $250 \times 125 \times 10.0$ & - & - & 738 & 532 & 472 & 422 \\
\hline & & EHS300× $\times 150 \times 10.0$ & - & - & 588 & 411 & 363 & 323 \\
\hline & & EHS $400 \times 200 \times 10.0$ & - & - & 357 & 226 & 187 & 162 \\
\hline & & EHS500×250×10.0 & - & - & 193 & 123 & 116 & 109 \\
\hline
\end{tabular}




\section{STRUCTURAL FIRE RESISTANT BEHAVIOUR}

After the temperature development curves (temperature vs. fire exposing time) under standard ISO fire were obtained through the thermal response analysis, a two-step stress-strain analysis is subsequently conducted to investigate the compressive behaviour of elliptical CFST stub columns. In the first step, a load corresponding to a load ratio of 0.5 (50\% of the sectional capacity at ambient temperature) is applied to the top of the composite column at ambient temperature. This load is maintained during the second step in which the temperature vs. fire exposing time curves previously obtained from the thermal analysis is imported. In the stress-strain analysis, the interaction between the steel hollow section and concrete core in the normal direction followed the "hard" contact pair mechanism, which allows pressure to be transmitted when the surface pairs are in contact. For the interaction in the tangent direction, a friction coefficient of 0.3 is introduced to consider the composite interaction between the steel tube and the concrete core ${ }^{[7]}$.

Espinos et al ${ }^{[7,8]}$ clearly described the deformation progress of long CFST columns under axial compressive load in fire. The deformation may be divided into four stages. The first stage is characterized by the expansion of the steel tube with the steel hollow section carrying the entire axial load applied to the composite column. The second stage starts when the steel section reached its yield stress at the elevated temperature and with the temperature raises further, the resistance of the steel hollow section decreases. The third stage is characterized by the concrete carrying the entire axial compressive load applied to the composite column due to the steel is yielded. The fourth stage begins with the reduction of the concrete strength due to the elevated temperature and leading to the complete composite column failed in fire. For the CFST stub columns, the four stages described by Espinos et al. were not clearly visible due to the expansion of stub column is relatively small. Therefore it would appear only two stages are observed for the stub column tests: expansion of the steel section followed by complete crushing at high temperature.

\subsection{Critical Steel Temperature and Critical Fire Exposure Time}

In this paper, the critical steel temperature is defined as the average steel temperature when the column experience progressive deformation and at which the steel material also reached its yield stress. The critical fire exposure time is the fire exposure time when the steel tube temperature reached the above mentioned critical steel temperature.

Figure 5 shows the typical relationships of axial shortening vs. fire exposing time and axial shortening vs. steel temperature for $200 \times 100 \times 10$ EHS with various fire protection options. It can be observed from the curves, the critical fire exposure times are evidently different although the critical steel temperatures are close. Obviously, the critical fire time of steel hollow section (US) without intumescent coating and concrete infill is the shortest followed by the CFST column without intumescent coating (UP). Although the critical fire time of the intumescent coating protected steel hollow section column (PS) is much longer than the critical fire time of unprotected hollow steel hollow section columns (US and UP), it is much shorter comparing with the critical fire exposing times of intumescent coating protected CFST columns (PP, PPA and PPB). As expected, the thicker the intumescent coating, the longer the critical fire exposing time. 

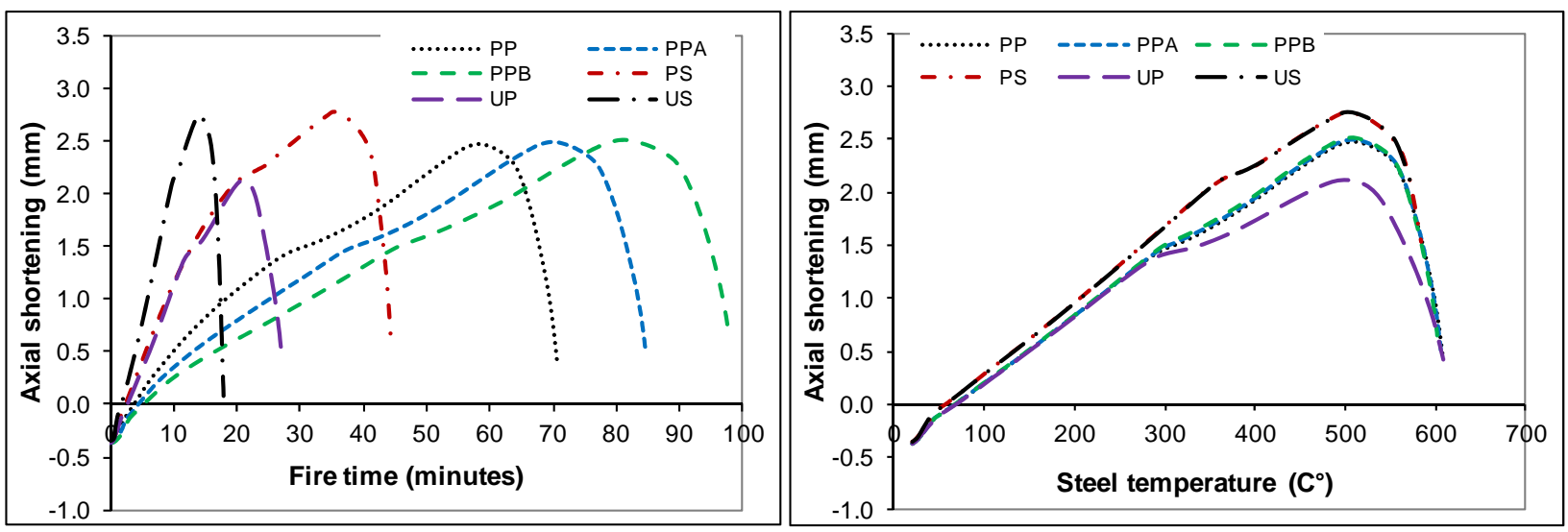

Figure 5. Relationships of Axial Shortening vs. Fire Exposing Time and Steel Tube Temperature for EHS200×100×10mm Hollow Sections with Different Intumescent Coating Thicknesses

Figures 6 and 7 present the effect of hollow section wall thickness and dimension to the critical fire exposing time and critical steel temperature. It can be seen in Figure 6 that with the steel wall thickness increases ( $A_{s} / A_{c}$ increase) but column outer dimension did not change, the critical fire time increases evidently but critical steel temperature remains unchanged. When the column section dimension increases ( $\mathrm{A}_{\mathrm{c}} / \mathrm{A}_{\mathrm{s}}$ increase), the critical fire exposing time increases evidently, but the critical steel temperatures remain the same. This indicates the merit of concrete infill and intumescent coating fire protection on structural fire behaviour of concrete filled steel stub columns under axial compression.
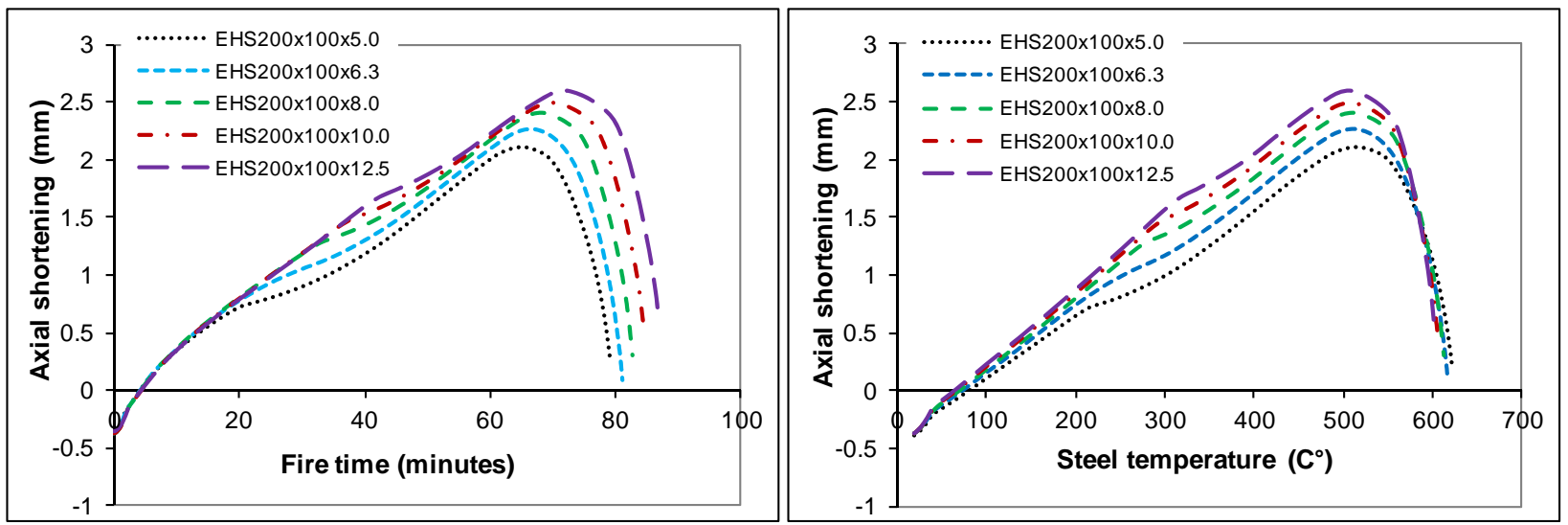

Figure 6. Relationships of Axial Shortening vs. Fire Exposing Time and Steel Tube Temperature of CFST Columns with 1.5mm Intumescent Coating and Different Wall Thickness

Table 2 summarizes the critical fire exposure time and critical steel temperature for all the selected columns, concrete infill and intumescent coating increases the critical fire exposing time and promotes steel critical temperature. From this study, with the wall thickness increased from $5.0 \mathrm{~mm}$ to $12.5 \mathrm{~mm}$, the critical fire exposure time increased by up to $9 \%$, with the exception of the unfilled steel hollow sections with or without intumescent coating (US, PS) where the increased of the critical fire duration is up to 59\% due to the increases in the wall thickness. For CFST columns with or without intumescent coating (UP, PP, PPA and PPB), with the tube wall thickness increased, the critical steel temperature decreased, but for steel hollow section without the concrete infill (US, PS), the critical steel temperature increased with the wall thickness increased.

The critical fire exposing duration increased with the column major diameter changed from 200mm 
to 500mm for concrete filled columns (UP, PP, PPA and PPB). However, for the unfilled steel hollow sections (US, PS), the increase of both critical fire exposing time and critical steel temperature were not evident. The comparison clearly indicated that the merit of application of concrete infilling and intumescent coating fire protection for composite members in fire.
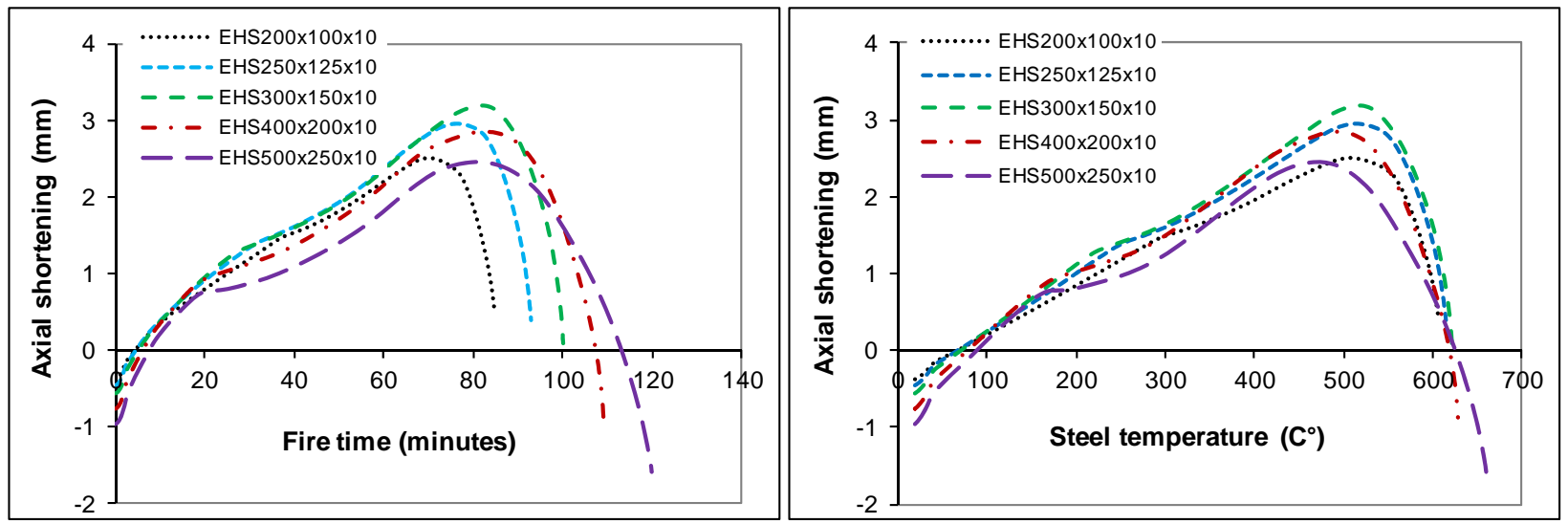

Figure 7. Relationships of Axial Shortening vs. Fire Exposing Time and Steel Tube Temperature for CFST Elliptical Columns with 1.5mm Intumescent Coating and Different Section Sizes

Table 2. Summary of Critical Fire Exposing Time and Steel Tube Temperatures for Selected Hollow Sections with Different Intumescent Coating and Concrete Infill Options

\begin{tabular}{|c|c|c|c|c|c|c|c|c|c|c|c|c|}
\hline \multirow[b]{2}{*}{ Hollow sections } & \multicolumn{2}{|l|}{ US } & \multicolumn{2}{|l|}{ PS } & \multicolumn{2}{|l|}{ UP } & \multicolumn{2}{|l|}{$\mathrm{PP}$} & \multicolumn{2}{|l|}{ PPA } & \multicolumn{2}{|l|}{ PPB } \\
\hline & $\begin{array}{l}\text { Time } \\
(\mathrm{min})\end{array}$ & $\begin{array}{l}\text { Temp } \\
\left({ }^{\circ} \mathrm{C}\right)\end{array}$ & $\begin{array}{l}\text { Time } \\
(\mathrm{min})\end{array}$ & $\begin{array}{l}\text { Temp } \\
\left({ }^{\circ} \mathrm{C}\right)\end{array}$ & $\begin{array}{l}\text { Time } \\
(\min )\end{array}$ & $\begin{array}{l}\text { Temp } \\
\left({ }^{\circ} \mathrm{C}\right)\end{array}$ & $\begin{array}{l}\text { Time } \\
(\mathrm{min})\end{array}$ & $\begin{array}{l}\text { Temp } \\
\left({ }^{\circ} \mathrm{C}\right)\end{array}$ & $\begin{array}{l}\text { Time } \\
(\min )\end{array}$ & $\begin{array}{l}\text { Temp } \\
\left({ }^{\circ} \mathrm{C}\right) \\
\end{array}$ & $\begin{array}{l}\text { Time } \\
(\mathrm{min})\end{array}$ & $\begin{array}{l}\text { Temp } \\
\left({ }^{\circ} \mathrm{C}\right)\end{array}$ \\
\hline EHS $200 \times 100 \times 5.0$ & 11.6 & 563 & 30.4 & 572 & 25.5 & 638 & 65.9 & 622 & 79.2 & 620 & 91.9 & 617 \\
\hline EHS200× $\times 100 \times 6.3$ & 12.7 & 566 & 34.1 & 574 & 26.0 & 629 & 67.1 & 616 & 80.8 & 616 & 93.6 & 613 \\
\hline EHS200 $\times 100 \times 8.0$ & 14.5 & 566 & 38.4 & 577 & 26.4 & 617 & 68.6 & 611 & 82.6 & 611 & 95.5 & 607 \\
\hline EHS200×100×10.0 & 16.3 & 569 & 42.2 & 580 & 26.9 & 605 & 70.3 & 607 & 84.5 & 605 & 97.7 & 602 \\
\hline EHS200×100×12.5 & 18.5 & 573 & 48.2 & 587 & 28 & 599 & 72.3 & 603 & 86.9 & 602 & 100.4 & 598 \\
\hline EHS250×125×10.0 & 16.4 & 567 & 42.4 & 578 & 28.7 & 615 & 76.3 & 614 & 92.9 & 614 & 107.5 & 613 \\
\hline EHS300×150×10.0 & 16.5 & 568 & 42.6 & 578 & 29.8 & 615 & 81.4 & 619 & 99.7 & 619 & 115.9 & 619 \\
\hline EHS400×200×10.0 & 16.6 & 567 & 42.8 & 577 & 31.5 & 626 & 88.4 & 630 & 109.0 & 629 & 127.6 & 627 \\
\hline EHS500×250×10.0 & 16.6 & 566 & 43.0 & 577 & 38.0 & 688 & 98.1 & 666 & 119.9 & 660 & 141.0 & 658 \\
\hline
\end{tabular}

\subsection{Assessment of Critical Steel Temperature of Elliptical CFST Stub Column Under Axial Compression}

Critical temperature is a very important parameter in the structural fire design and analysis. Based on the numerical research presented in this paper, the critical steel temperature changed with different wall thickness and sectional dimension as shown in Figure 8, therefore developing a simple formula to assess the critical steel temperature will be very useful for the structural engineers in their preliminary design. Due to the concrete infill, the critical steel temperature of an elliptical CFST column is higher than an identical unfilled elliptical hollow section column. Based on the numerical analyses conducted in this study, a simple method was developed for elliptical concrete filled stub columns with typical hot-rolled steel and normal weight concrete and a load ratio of 0.5. Equations (1) and (2) may be used to assess the critical steel temperature of elliptical CFST columns and elliptical hollow section columns respectively. Figure 8 compares the critical 
steel temperature of columns with various wall thickness, section dimensions and fire protection options and good agreement is obtained.

$$
\begin{aligned}
& T_{C r, C F S T}=595+\left(\frac{a+b}{150}\right)^{1.8}\left(\frac{100}{t}\right)^{1.1} \\
& T_{C r, H S}=560+\left(1-\frac{a+b}{1000}\right) t^{1.25}
\end{aligned}
$$

where,

$t$ : tube steel wall thickness (mm);

$a$ : longer outer radius of elliptical hollow section (mm);

$b$ : shorter outer radius of elliptical hollow section (mm);

$T_{C r, C F S T}$ : critical steel temperature of CFST column $\left({ }^{\circ} \mathrm{C}\right)$;

$T_{C r, H S:}$ critical steel temperature of empty hollow section column $\left({ }^{\circ} \mathrm{C}\right)$.
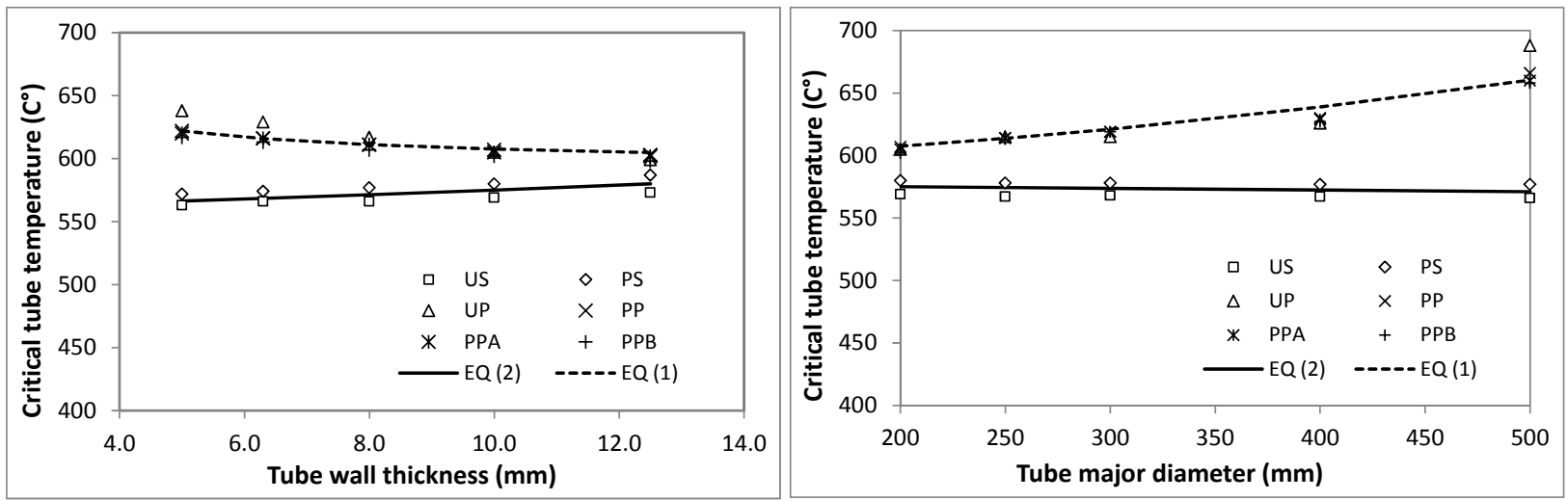

Figure 8. Comparison of Critical Steel Temperature obtained from Simple Method Equations (1) and (2) and FE Modelling Prediction

\subsection{Prediction of Maximum Axial Capacity Using a Simplified Method}

For CFST stub columns with typical cross-sectional shapes exposed to standard fire, the authors proposed a simple method to calculate the ultimate axial compressive load capacity by section strengths as shown in equation (3). However, in the previous research by Dai and Lam [9], the maximum dimensions of CFST columns were limited to $200 \mathrm{~mm}$ and without any fire protection. The research results presented in this section could justify the suitability of equation (3) for stub elliptical CFST columns with section dimension above $200 \mathrm{~mm}$ and with intumescent coating as additional fire protection.

$N_{y, f}=A_{s} f_{y, \theta s}+A_{c} f_{c, \theta c}$

where,

$A_{s}$ : steel tube cross sectional area $\left(\mathrm{mm}^{2}\right)$;

$A_{c}$ : concrete core cross sectional area $\left(\mathrm{mm}^{2}\right)$;

$N_{y, f}$ : sectional strength of CFST column in standard fire $(\mathrm{kN})$.

$f_{y}, \theta s$ : the yield strength of steel material at temperature $\theta_{s},\left(\mathrm{~N} / \mathrm{mm}^{2}\right)$.

$f_{c, \theta c}$ the concrete compressive strength at temperature $\theta_{c},\left(\mathrm{~N} / \mathrm{mm}^{2}\right)$. 
Based on the previous study by Dai and Lam [9], equation (3) might be used to assess the maximum axial load capacity of a CFST stub column at elevated temperature. $f_{y}, \theta$ is the reduced steel strength according to EN1993-1-2 for the steel at elevated temperature. The temperature of concrete core is related to the steel temperature with the coefficient varying with different sectional shapes. The proposed coefficients were: $\theta_{c}=0.7 \theta_{s}$ for CFST columns with circular section, $\theta_{c}=$ $0.6 \theta_{s}$ for CFST columns with elliptical section and $\theta_{c}=0.45 \theta_{s}$ for CFST columns with square and rectangular sections. Due to all the selected CFST stub columns in this paper were elliptical sections, therefore, $\theta_{c}=0.6 \theta_{s}$ was used. $f_{c, \theta c}$ is the reduced concrete strength in accordance to the concrete core temperature, $\theta_{c}$ as given in EN1994-1-2.

Figure 9 shows the comparison of maximum axial compressive load of the elliptical CFST columns with various cross sectional dimensions, fire protection options at critical steel temperatures, obtained from numerical analysis and equation (3). It shows that stub elliptical CFST columns without any fire protection (UP) and with intumescent coating (PP, PPA, PPB), the maximum axial compressive load predicted by equation (3), $N_{c, E q}$ is very close to the maximum axial compressive load predicted by FE model, $N_{c}$, FE for column sectional dimensions up to $400 \times 200 \mathrm{~mm}$. For the column section dimension larger than $400 \times 200 \mathrm{~mm}$, equation (3) would appear to under-estimate the maximum axial compressive load however on the conservative side. For the unfilled elliptical hollow section columns (US and PS) under standard ISO fire, regardless of the intumescent coating fire protection, the maximum axial compressive load predicted by FE modelling is lower than the section strength calculated using equation (3) by ignoring the concrete term $\left(A_{c} f_{c, \theta c}=0\right)$. This is because the maximum load obtained from the FE model considered the effect of local buckling of elliptical hollow section and this was ignored by the simplified method. However, as shown in Figure 9, for empty elliptical hollow section stub columns with different section dimensions, the reduction of maximum load by local buckling was similar and can be corrected by multiplying a constant coefficient of 0.77 .

The comparison in this section has shown that the simplified method could be used to predict the maximum axial capacity for stub elliptical CFST columns with different sectional dimensions and intumescent coating fire protection. In addition, an important merit from the concrete core has emerged that the concrete core not only provide substantial enhancement to the axial compressive capacity of the composite columns, but also contribute to the development of full steel sectional strength by delaying or eliminating the local buckling of steel sections in fire.

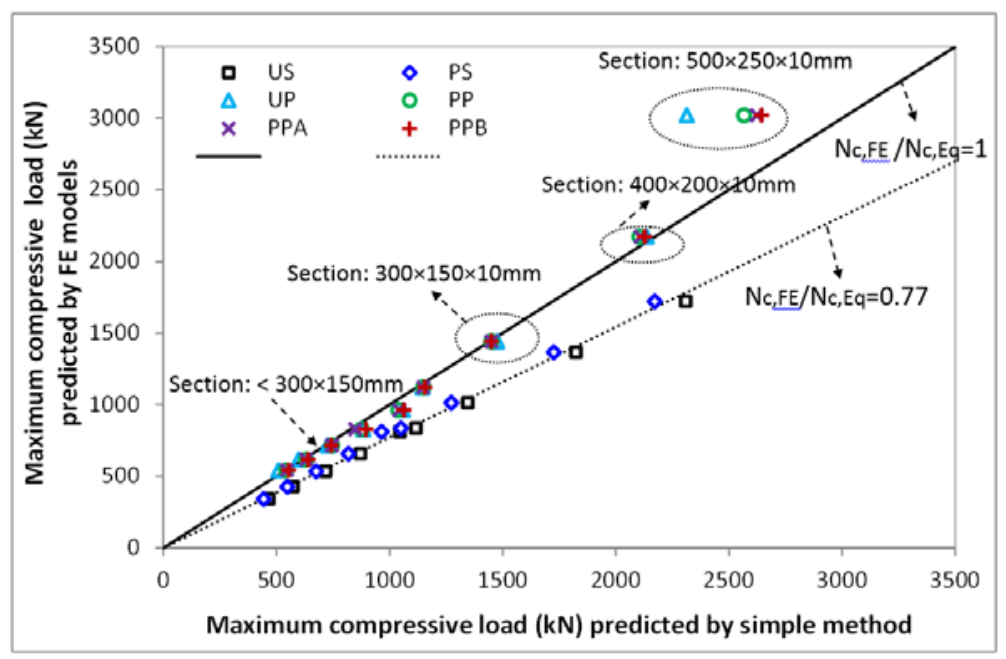

Figure 9. Comparison of Critical Loads obtained from Simple Method Prediction and FE Prediction 


\section{CONCLUSIONS}

The research presented in this paper discussed the effect of concrete infill and intumescent coating to the temperature development and structural fire behaviour of elliptical CFST stub columns under axial compression. The following conclusions could be drawn:

(1) Concrete core reduced steel temperature of elliptical CFST column, however for the commonly used steel elliptical hollow sections (sections range from $200 \times 100 \times 5 \mathrm{~mm}$ to $200 \times 100 \times 12.5 \mathrm{~mm}$ and $200 \times 100 \times 10 \mathrm{~mm}$ to $500 \times 250 \times 10 \mathrm{~mm}$ adopted in this paper), the concrete core was unable to limit the steel temperature to $550^{\circ} \mathrm{C}$ for 60 minutes under standard ISO fire exposure. Only by applying intumescent coating to the CFST columns, the steel temperature may be limited to below $550^{\circ} \mathrm{C}$.

(2) For elliptical CFST stub columns with identical outer sectional dimensions, it appears that as the steel tube wall thickness increases, the steel temperature reduced and the core centre temperature increased. However if the wall thickness was kept constant (say $10 \mathrm{~mm}$ ) with the column section dimension increasing from $200 \times 100 \times 10 \mathrm{~mm}$ to $500 \times 250 \times 10 \mathrm{~mm}$, the steel temperature decreased slightly for the columns with intumescent coating, and the concrete core centre temperature reduced significantly due to the increases of the heat flux conducting distance.

(3) When identical elliptical stub columns under a constant axial compressive load ratio and standard ISO fire, the unprotected and unfilled hollow section (US) has the shortest critical fire exposing time, followed by the unprotected concrete filled hollow section (UP). Although the critical fire time of the intumescent coating protected hollow section (PS) is much longer than the critical fire time of unprotected hollow sections (US and UP), it is shorter than the critical fire exposing time of intumescent coating protected CFST columns (PP, PPA and PPB). As expected for stub columns with different steel hollow sections (various wall thickness and various outer sectional dimensions), the critical fire exposing time change agreed with the above conclusions and the thicker the intumescent coating, the longer the critical fire period.

(4) For elliptical CFST stub columns with identical sectional outer dimensions subjected to the same axial compressive load ratio and standard ISO fire, it appears that as the wall thickness increases, the critical fire exposing time increased significantly except for the unprotected concrete filled steel hollow section (UP), the increases of the critical fire exposing time was not evident. The effect of wall thickness to critical steel temperature is different from critical fire exposing time, in which the critical temperature decreased with the increases in wall thickness although for unfilled steel hollow sections (US, PS), the critical steel temperature shows an increasing trend.

(5) As expected, the critical fire exposing time increased with the outer sectional dimension of the elliptical CFST stub columns increasing from $200 \times 100 \times 10 \mathrm{~mm}$ to $500 \times 250 \times 10 \mathrm{~mm}$. In addition, the critical tube steel temperature of concrete filled stub columns (UP, PP, PPA and PPB) increased following the outer sectional dimension increasing, but the critical steel temperatures and critical fire exposure time of unfilled steel hollow sections (US, PS) had little change.

(6) The proposed equations might be used to assess the critical temperatures of stub elliptical CFST columns under axial compression (load ratio of 0.5) at elevated temperature regardless of the existence of intumescent coating fire protection. 
(7) The research presented in this paper demonstrates the merits of concrete filled steel hollow sections and intumescent coating fire protection over unfilled steel hollow sections in fire resistance design and application. This information supports the combined application of concrete infill and intumescent coating in fire-resistant structural design.

(8) The proposed equations (1) and (2) are numerically verified by a limited range of the specimens, i.e. elliptical cross sections stub columns with a load ratio of 0.5 . Further experimental study is required to validate the accuracy of these equations for CFST columns with different sectional shapes, load ratios and slenderness.

\section{ACKNOWLEDGEMENT}

The research reported in this paper is funded by the research grant from the Engineering and Physical Science Research Council (EP/G002126/1) in the UK who are gratefully acknowledged.

\section{REFERENCES}

[1] Tao, Z., Han, L.H., Uy, B. and Chen, X., "Post-fire Bond between the Steel Tube and Concrete in Concrete-filled Steel Tubular Columns”, Journal of Constructional Steel Research 2011, Vol. 67, No. 3, pp. 484-496.

[2] Han, L.H. and Lin, X.K., "Tests on Cyclic Behavior of Concrete-Filled Hollow Structural Steel Columns after Exposure to the ISO-834 Standard Fire”, ASCE Journal of Structural Engineering, 2004, Vol. 130, No. 11, pp. 1807-1819.

[3] Han, L.H., Lin, X.K. and Yang, Y.F., "Cyclic Performance of Concrete Filled Steel Tubular Columns after Exposure to Fire: Analysis and Simplified Model”, Advances in Structural Engineering, 2008, Vol. 11, No. 4, pp. 455-473.

[4] Huo, J., Huang, G. and Xiao, Y., "Effects of Sustained Axial Load and Cooling Phase on Post-fire Behaviour of Concrete-filled Steel Tubular Stub Columns”, Journal of Constructional Steel Research, 2009, Vol. 65, No. 8-9, pp. 1664-1676.

[5] Zha, X.X., "FE Analysis of Fire Resistance of Concrete Filled CHS Columns”, Journal of Constructional Steel Research, 2003, Vol. 59, No. 6, pp. 769-779.

[6] Hong, S. and Varma, A.H., "Analytical Modelling of the Standard Fire Behavior of Loaded CFT Columns”, Journal of Constructional Steel Research, 2009, Vol. 65, No. 1, pp. 54-69.

[7] Espinos, A., Romero, M.L. and Hospitaler, A., "Advanced Model for Predicting the Fire Response of Concrete Filled Tubular Columns”, Journal of Constructional Steel Research 2010, Vol. 66, No. 8-9, pp. 1030-1046.

[8] Espinos, A., Gardner, L., Romero, M.L. and Hospitaler, A., "Fire Behaviour of Concrete Filled Elliptical Steel Columns", Thin-Walled Structures, 2011, Vol. 49, No. 2, pp. 239-255.

[9] Dai, X.H. and Lam, D., "Shape Effect on the Behaviour of Axially Loaded Concrete Filled Steel Tubular Stub Columns at Elevated Temperature” Journal of Constructional Steel Research, 2012, Vol. 73, No. 6, pp. 117-127.

[10] Corus Construction \& Industrial, Fire Resistance of Steel-framed Building, 2006 Edition (online).

[11] Dai, X.H., Wang, Y.C. and Bailey, C.G., "Effects of Partial Fire Protection on Temperature Developments in Steel Joints Protected by Intumescent Coating”, Fire Safety Journal 2009, Vol. 44, pp. 376-86. 
[12] Dai, X.H., Wang, Y.C. and Bailey, C.G., "A Simple Method to Predict Temperatures in Steel Joints with Partial Intumescent Coating Fire Protection”, Fire Technology Journal 2010, Vol. 46, pp. 19-35.

[13] BS EN 1994-1-2, Eurocode 4: Design of Composite Steel and Concrete Structures, Part 1-2: General Rules-Structural Fire Design, British Standards Institution, London, 2005.

[14] ISO 834, Fire Resistance Tests, Elements of Building Construction. International Organization for Standardization, Geneva 1975.

[15] BS EN 1993-1-2, Eurocode 3: Design of Steel Structures, Part 1.2: General RulesStructural Fire Design, British Standards Institution, London 2005.

[16] BS EN 1991-1-2, Eurocode 1: Actions on Structures, Part 1-2: General Actions-Actions on Structures Exposed to Fire, British Standards Institution, London 2002.

[17] Ding, J. and Wang, Y.C., "Realistic Modelling of Thermal and Structural Behaviour of Unprotected Concrete Filled Tubular Columns in Fire”, Journal of Constructional Steel Research, 2008, Vol. 64, pp. 1086-1102. 